\title{
Author Correction: Extraordinary human energy consumption and resultant geological impacts beginning around 1950 CE initiated the proposed Anthropocene Epoch
}

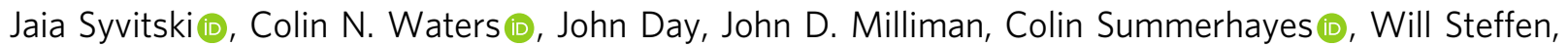
Jan Zalasiewicz, Alejandro Cearreta (1), Agnieszka Gałuszka (1), Irka Hajdas (1), Martin J. Head(D, Reinhold Leinfelder (1), J. R. McNeill, Clément Poirier (D, Neil L. Rose (D), William Shotyk, Michael Wagreich (1) \& Mark Williams

Correction to: Communications Earth \& Environment https://doi.org/10.1038/s43247-020-00029-y, published online 16 October 2020.

The original version of this Review contained errors in which the units of EJ/y were incorrectly labelled as TJ/y; the errors occurred in Fig $1 \mathrm{~b}$ (title and caption), Fig. 3a, b (X-axis), Fig. 4 (Y-axis for row 1; X-axis for column 2 and caption), Table 2 (column 1, row 3), Supplementary Table 1 (column 5 heading and caption) and Supplementary Table 2 (column 3 heading and caption).

These errors have been corrected in both the PDF and HTML versions of the Review and the HTML has been updated to include a corrected version of the Supplementary information, which is additionally attached to this Correction.

Published online: 02 November 2020

\section{Additional information}

Supplementary information is available for this paper at https://doi.org/10.1038/s43247-020-00049-8. 